\title{
Influence of silica fume on the dynamic properties of concrete
}

\author{
Benmammar M*, Boukli H S M E
}

EOLE Laboratory / Civil Engineering Department, University of Tlemcen, B.P. 230 Chetouane, Tlemcen 13000-Algéria.

* Corresponding Author: mohammed.benmammar@yahoo.fr

\begin{tabular}{l} 
Received: 10-02-2018 Revised: 27-04-2018 \\
\hline Abstract. Ultrasonic pulse velocity and resonance frequency methods are non-destructive \\
tests that allow the evaluation and control of building materials. They have been used to \\
determine the dynamic properties of concrete, which are used in the design and control of \\
structures and which are the key elements of the dynamics of materials. \\
In this study, we chose a non-destructive approach to quantify -in laboratory-, the influence \\
of adding "silica fume" on ordinary concrete's dynamic characteristics. However, several \\
concrete mixtures have been prepared with limestone aggregates. The experimental plan \\
used, allowed us to determine the dynamic elasticity modulus and the dynamic rigidity \\
modulus of different formulated concretes.
\end{tabular}

Key words: Concrete, Non-destructive tests, Dynamic elasticity modulus, Dynamic rigidity modulus, Additions, Compressive Strength.

\section{Introduction}

The non-destructive testing is a fundamental area of research, which allows obtaining the quality and the degradation state of building materials. Some characteristics of concrete, such the ultrasonic pulse velocity test, which is standardized by ASTM C597-09 (2003) allows the control of the quality of the materials and makes it possible to estimate the mechanical properties. It is a method based on the propagation speed of elastic waves in a material. The speed measurement system according to certain steps makes it possible to calculate the speed of propagation of the longitudinal or compression waves, which are the fastest elastic waves and the longitudinal modulus of elasticity, compressive strength, porosity, etc., are essential in the design and control of structures. The dynamic modulus of elasticity is considered equal to the elastic modulus, tangent at the origin and determined in static testing. The dynamic modulus of elasticity can easily be measured by estimating the static modulus, which must be known to design concrete structures. In order to find the relationship between the static and dynamic moduli and confirm the influence of additions, such as silica fume (SF), a non-destructive approach, based on the measurement of the resonant frequency on cylindrical concrete specimens $\left(16 \times 32 \mathrm{~cm}^{2}\right)$ was used (Bouakkaz, 2012; ASTM C 597-02, 2003; Dimitrios and Shiotani, 2009; Mirjana et al. 2014; Fathollah and Payam, 2012).

The use of supplementary cementitious materials as SF, as part of binders for concrete, has increased worldwide. Furthermore, their use as mineral additives, to partially replace cement, could somehow save non-renewable resources required for the production of cement, and may therefore contribute, in some way, to the durability of concrete structures (Mehta and Monteiro, 2006; Baroghel-bouny, 2005; Gesoglu and Ozbay, 2007).

This paper presents the results of the influence of supplementary cementing materials on the dynamic properties of ordinary concretes. The elastic modulus (longitudinal and transversal) of ordinary concrete, containing $05 \% \mathrm{SF}$, is compared with those of the reference concrete (RC) with similar mixing proportions but without supplementary cementing materials. In addition, 
the existing standards indicate that appropriate arrangements on the potential influence of additions on the estimation of the elastic modulus are actually lacking.

\section{Characterization of used materials}

The cement used in this study meets the Algerian standard (NA 44); it is of type (CPJ CEM II/A 42.5) and comes from the National Cement Company in the town of BeniSaf, province (Wilaya) of Ain Temouchent, Algeria. To prepare different types of concrete, drinking water was used, from the public water supply network, from the district (Daïra) of Chetouane, in the city of Tlemcen, Algeria.

The aggregates used are from the big quarry of the National Company of Aggregates (ENG), in Djebel Abiod, in Tlemcen, Algeria, and silca fume (SF) is from the Teknachem Algeria (sidi bel Abbes). The aggregates are marketed in various granular classes: sand $0 / 3$ and gravels $3 / 8$, $8 / 16$ and $16 / 25$.

Analysis on the chemical composition and physical properties of cement and SF are reported in Table 1. The properties of the aggregates used were determined in our laboratory (Boukli and Ghomari, 2007; Boukli et al., 2009; Boukli, 2010).

Table 1. Chemical compositions and physical properties of cement and SF.

\begin{tabular}{|c|c|c|}
\hline Item & CEM II & SF \\
\hline \hline $\mathrm{SiO}_{2}$ & 22.17 & 95 \\
\hline $\mathrm{Al}_{2} \mathrm{O}_{3}$ & 6.18 & 0.5 \\
\hline $\mathrm{Fe}_{2} \mathrm{O}_{3}$ & 3.62 & 1 \\
\hline $\mathrm{C}_{\mathrm{a}} \mathrm{O}$ & 59.45 & 0.5 \\
\hline $\mathrm{M}_{\mathrm{g}} \mathrm{O}$ & 1.05 & 1 \\
\hline $\mathrm{SO}_{3}$ & 3.63 & 0 \\
\hline $\mathrm{P}_{2} \mathrm{O}_{5}$ & 0.18 & 0.01 \\
\hline $\mathrm{T}_{\mathrm{i}} \mathrm{O}_{2}$ & 0.43 & 1 \\
\hline $\mathrm{LOI}$ & 2.62 & 0 \\
\hline Density & 3.071 & 2.2 \\
\hline Blaine specific surface $\left(\mathrm{cm}^{2} / \mathrm{g}\right)$ & 3598 & 220000 \\
\hline
\end{tabular}

\section{Experimental program and test methods}

\subsection{Experimental program}

The concretes are formulated on the basis of optimized granular skeletons Boukli (2010) with a $\mathrm{w} / \mathrm{c}$ ratio equal to 0.5 and the percentage of silica fume $5 \%$ (Table 2). Eighty-four (24) cylindrical specimens $\left(16 \times 32 \mathrm{~cm}^{2}\right)$ were prepared to determine the resonance frequency at different times (3, 7, 14 and 28 days), (24) other cylindrical specimens $\left(16 \times 32 \mathrm{~cm}^{2}\right)$ for measuring ultrasonic pulse velocity at maturity $(3,7,14$ and 28 days).

The concretes under study were prepared in accordance with the standards in use, Afnor (2002a), Afnor (2002-b) and Algerian Standards (1992).

Table 2. Composition of RC Boukli (2010).

\begin{tabular}{|c|c|}
\hline Constituents & Quantities $\left(\mathrm{Kg} / \mathrm{m}^{3}\right)$ \\
\hline \hline Cement CPJ CEM II/A 42,5 & 350 \\
\hline Gravel $(16 / 25)$ & 533 \\
\hline Gravel $(8 / 16)$ & 432 \\
\hline Gravel $(3 / 8)$ & 144 \\
\hline Sand $(0 / 3)$ & 660 \\
\hline Water & 175 \\
\hline
\end{tabular}




\subsection{Test methods}

\subsubsection{Measurement of dynamic characteristics}

The test apparatus used is the one required by ASTM C 215-02; the method 'Standard Test Method for Fundamental Transverse, Longitudinal, and Torsional Resonant Frequencies of Concrete Specimens' was used. The equipment, which meets the ASTM requirements, was designed by various trade organizations. It includes an electromechanical transmitter placed at one end of the test tube, a receiver at the other end, and a device for measuring the resonant frequency of the medium, according to standard NF P18-414 (Afnor, 2002-b).

To measure the dynamic modulus of elasticity $E_{d}$, the test seeks to evaluate the longitudinal resonance frequency of a cylindrical concrete specimen by placing the emitter and the receiver on the same longitudinal axis of the specimen, as shown in Figure 1.

\section{Acoustic vibrator}

\section{Accelerometer}
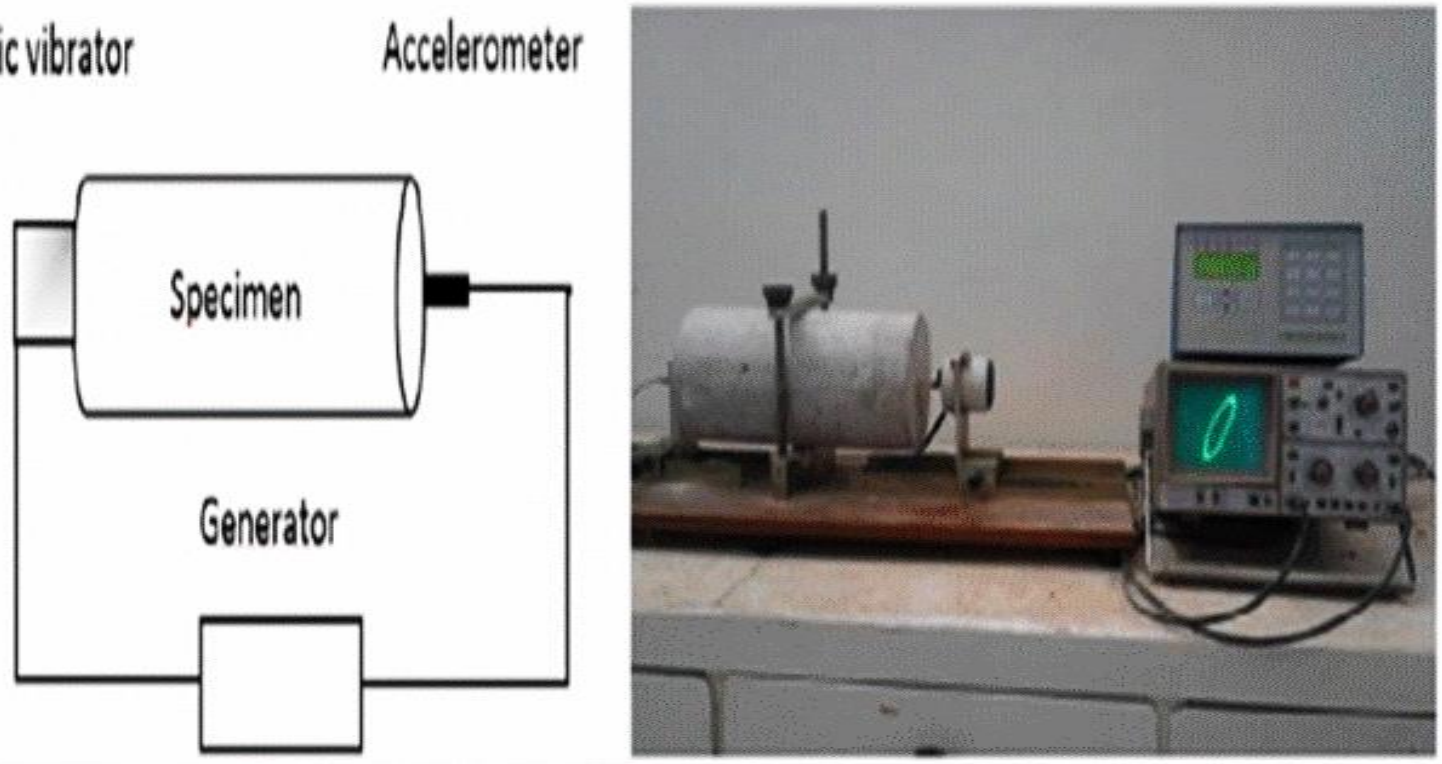

Fig 1. Schematic diagram of the longitudinal resonance testing.

This arrangement of the transmitter and receiver generates longitudinal vibrations, parallel to the main axis of the specimen. The dynamic longitudinal modulus of elasticity $E_{d}$ is obtained by the use of the theory of elastic wave propagation, assuming that the material is rigid and continuous, and exhibiting an elastic behavior. This method is used for homogeneous and isotropic materials, but can also be applied to a heterogeneous material, such as concrete, when the test tube dimensions are large compare to the size of the components (Han and Kim, 2004; Khan, 2012; Giner et al 2012). The frequency is varied until a resonant value is found.

We have the following equation:

$N=\frac{m^{2} K}{2 \pi L^{2}} \sqrt{\frac{E}{\rho}}$

According to Equation 1, we found E:

$E=\frac{4 \pi^{2} L^{4} N^{2} \rho}{K^{2} m^{4}}$

Where, $E$ is the dynamic modulus of elasticity, $\rho$ is the material density, $L$ is the length of the sample, $N$ is the resonance frequency, $K$ is the radius of gyration of the section about an axis 
perpendicular to the plane of bending and $m$ is a constant ( 4.73 for the fundamental mode of vibration).

The dynamic modulus of elasticity is calculated from the fundamental frequency of longitudinal vibration of the sample by the following equation:

$E=4 L^{2} \rho N^{2}$

The two equations (1) and (3) obtained are used to solve the differential equation of motion (Hassan and Jones, 2012).

The dynamic shear modulus is calculated using the same way as the dynamic modulus of elasticity (Equ.3), simply replacing $N_{L}$ by $N_{T}$ representing the transversal resonance frequency which is given by the following equation:

$G=4 L^{2} \rho N^{2}$

\subsubsection{Measurement of ultrasonic velocities}

The fundamental idea of the method is based on recording the propagation of mechanical waves and preferably compression waves, because it is the fastest wave. An ultrasonic wave pulse in the concrete is generated at a point on the surface of the sample and the time required for the wave to travel from that point to the other surface is measured (Fig 2).

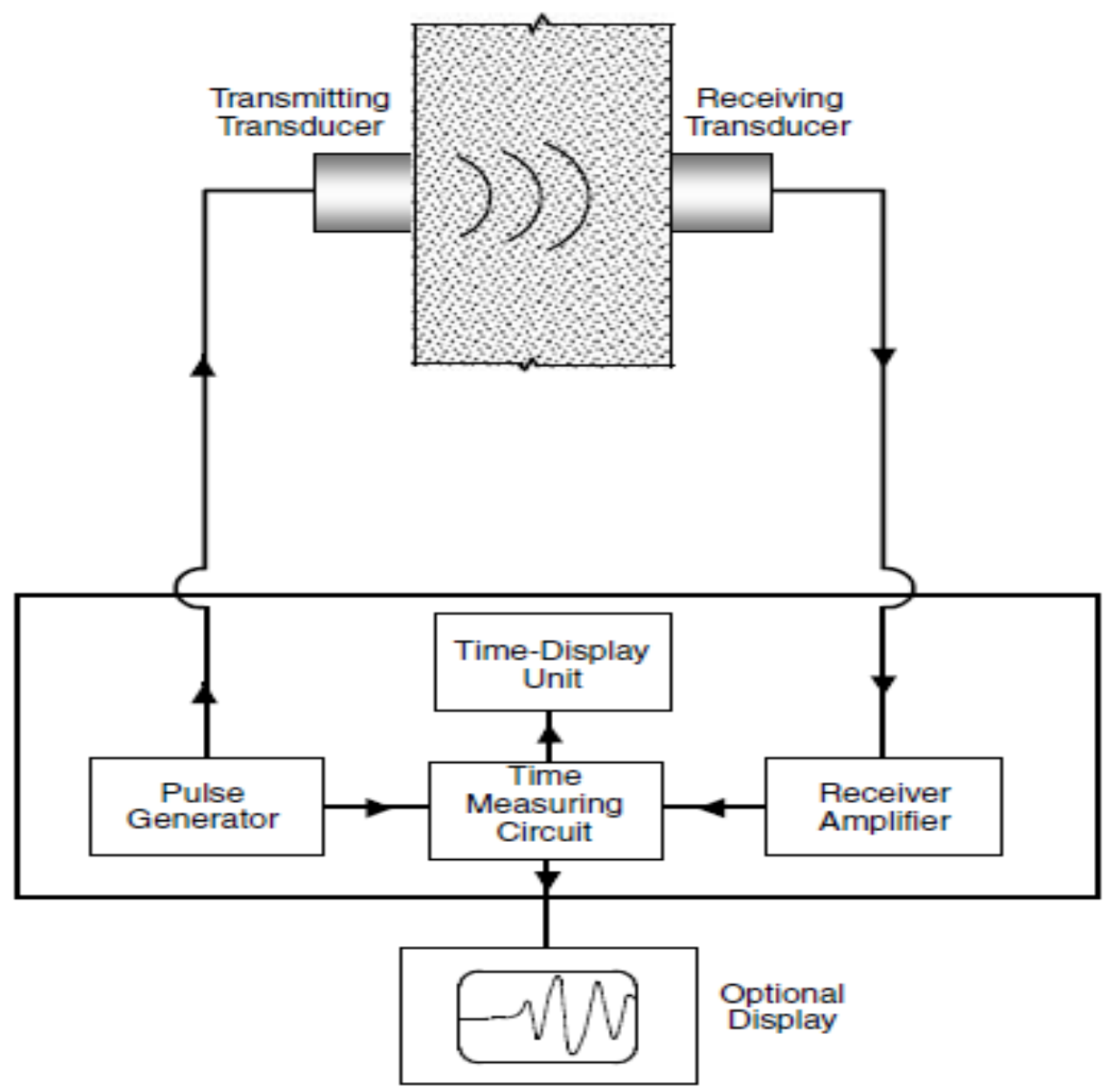

Fig 2. Schematic representation of an ultrasound test.

The positioning of the sensors and the measurement of the distance are important. However, two-sided access is not required. Knowing the distance between these two points, the pulse velocity can be determined. However, several factors affect the rate of impulse in concrete, such 
as the size, shape of large aggregates, water/binder ratio, degree of consolidation, condition of concrete curing and presence of reinforcement (Malhotra et al., 2004).

\section{Results and discussion}

\subsection{Influence of the silica fume on the longitudinal modulus of elasticity}

FIG. 3 shows the influence of the additional addition on the dynamic modulus with a w/c ratio equal to 0.5 . This figure shows that the greatest value of the dynamic modulus of elasticity is obtained from the concrete containing $5 \%$ of silica fume (SF) followed by the reference concrete (RC). The substitution of 5\% SF give superior values to those of RC and this is during the curing period to the age of 28 days.

In addition, the dynamic elasticity modulus obtained for the 5\% SF5 concrete mix is higher than that of the reference concrete, throughout the duration of the hardening, because she has a very high finesse.

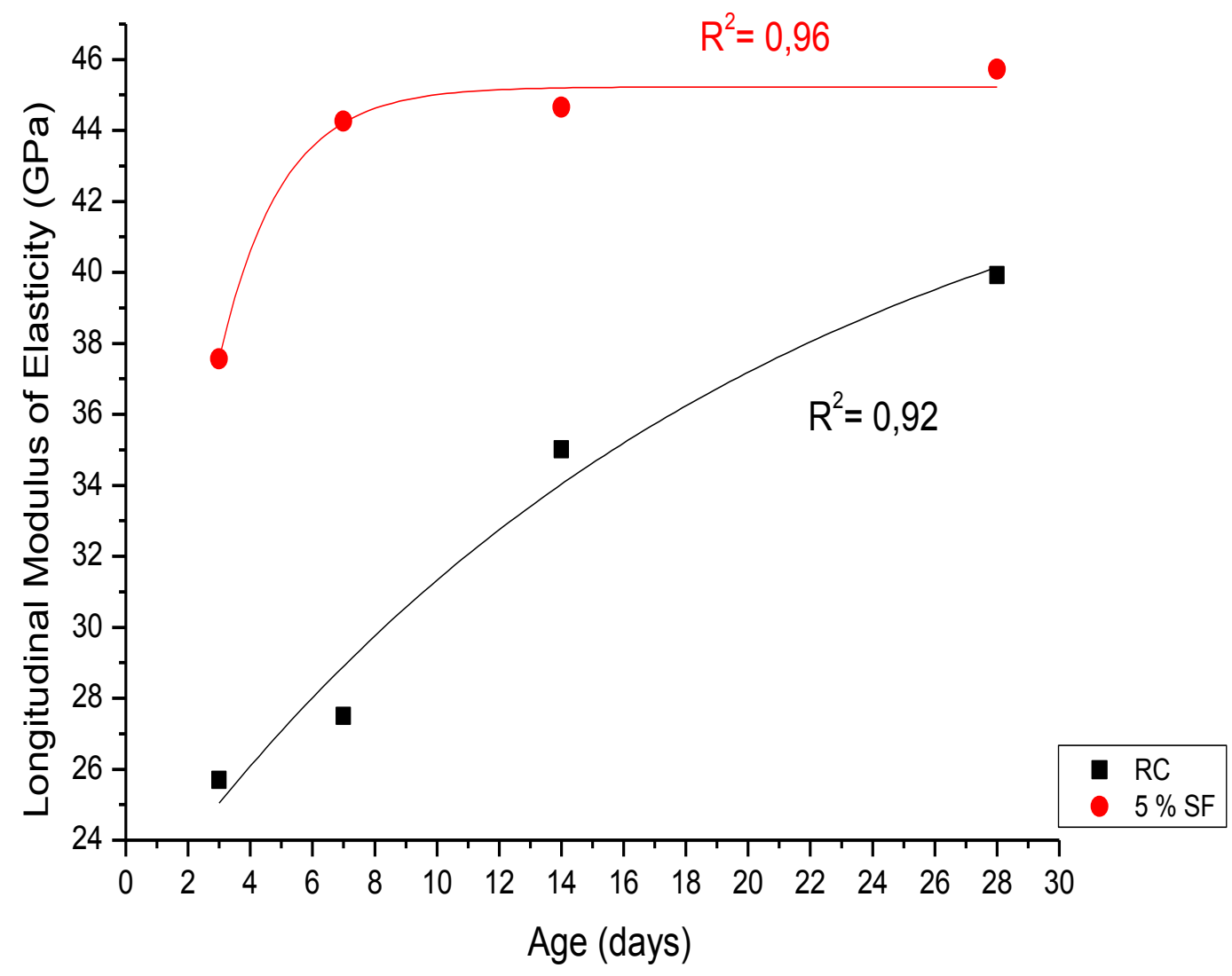

Fig.3. Influence of silica fume on the longitudinal modulus of elasticity

\subsection{Influence of the silica fume on the transversal modulus of elasticity}

FIG. 4 is the same as Fig. 3, shows the influence of the silica fume on the modulus of transverse elasticity for a w/c ratio equal to 0.5 . This figure shows that the greatest value of the modulus of elasticity of stiffness is obtained from the concrete containing $5 \%$ of silica fume, followed by the reference concrete. 


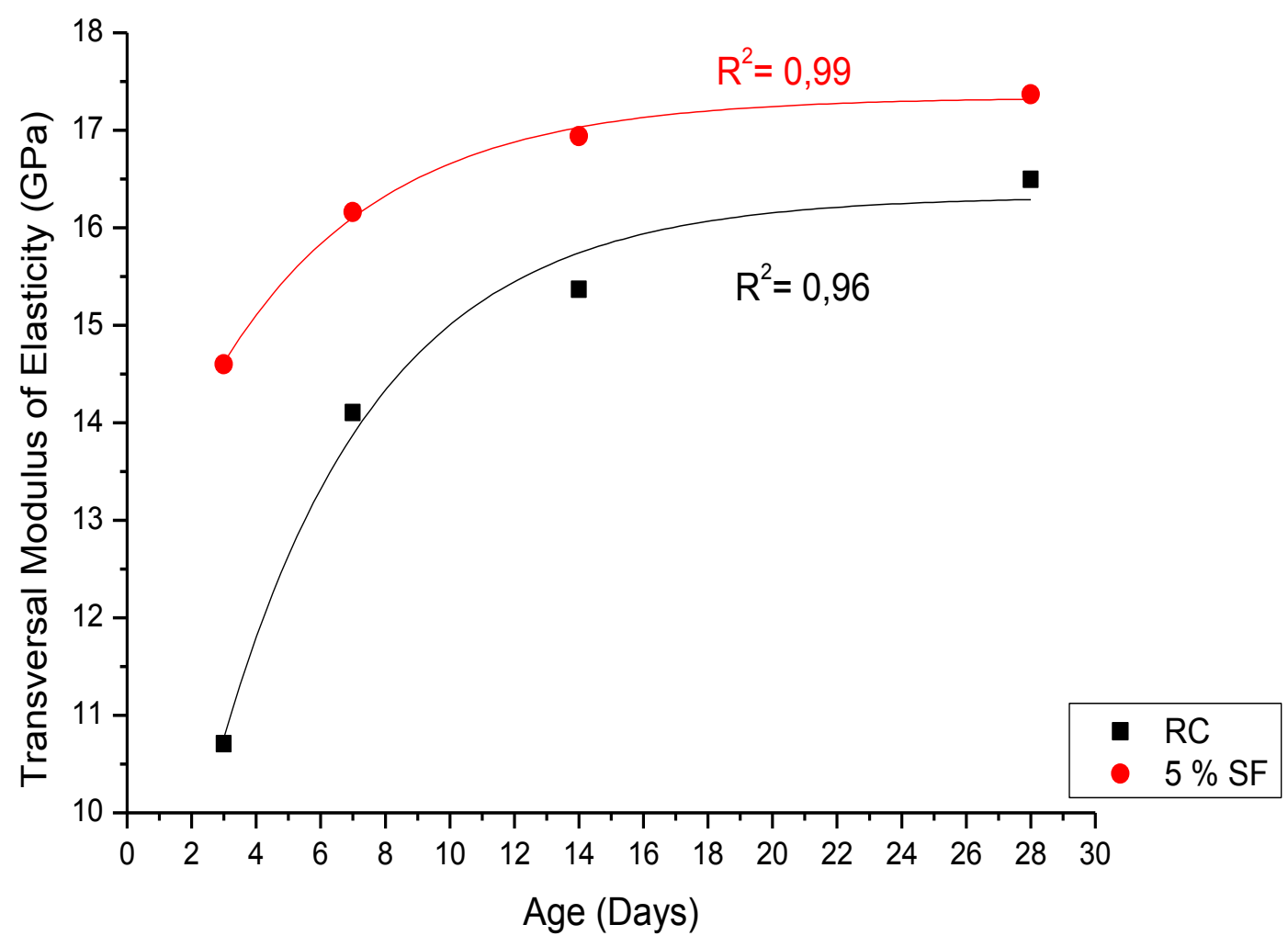

Fig.4. Influence of silica fume on the transversal modulus of elasticity

The trend lines give a large scatter of points, which can be justified by the coefficients of determination which exceed 0.9 in all cases. The curves presented in FIGS. 3 and 4 can be represented by a type of exponential equation:

$E_{d}=A e^{-\frac{X}{B}}+C$

\subsection{Influence of the silica fume on the ultrasonic pulse velocity}

The highest value of the UPV of Fig. 5 is obtained from the concrete containing 5\% SF, followed by the RC, although this difference is not so important.

For the concrete mixtures 5\% SF, the UPV values obtained are higher than those of the reference concrete during the entire curing period due to the formation of hydrates, in addition to the calcium silicates (C-S-H).

The trend lines give a large scatter of points, which can be justified by the coefficients of determination that exceed 0.9. FIG. 5 concerning the UPV can be represented by a type of exponential equation:

$U P V=A e^{(B x)}+C$ 


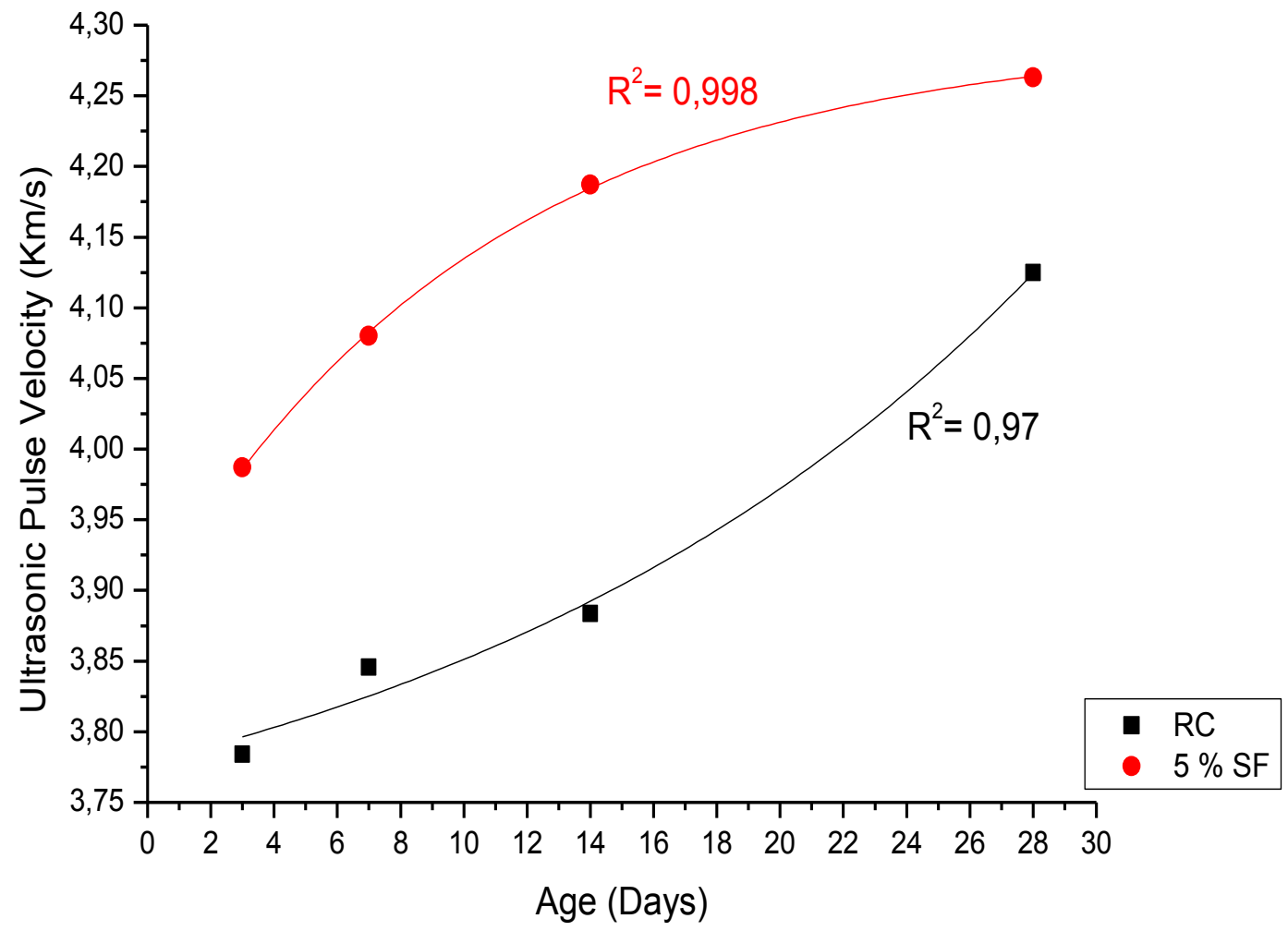

Fig.5. Influence of silica fume on the ultrasonic pulse velocity

\section{Conclusions}

Based on the results presented earlier in this document, the following conclusions can be made:

- The $05 \%$ silica fume of addition has a direct influence on the modulus of transverse and dynamic elasticity.

- The values of the dynamic and transverse modulus of elasticity of the concrete containing $5 \%$ of the silica fume are higher than those of the reference concrete. The substitution of silica fume tends to increase the values of dynamic, transverse elastic modulus and ultrasound pulse rate at young age up to the 28-day curing age.

\section{References}

Afnor (2002-a). Concrete and its constituents. Tome 1: specifications of concrete and its constituents. 5th ed. Paris: French Association of Normalization. p. 431.

Afnor (2002-b). Concrete and its constituents. Tome 2: test methods of concrete. 5th ed. Paris: French Association of Normalization. p. 510.

Algerian Standards (1992). Publishing and distribution by Abou Hamou Moussa. Algier: 192.

ASTM C 215-02. Standard test method for fundamental transverse, longitudinal and torsional.

ASTM Test Designation C 597-02. (2003). Standard Test Method for Pulse Velocity through Concrete. Annual Book of ASTM Standards.

ASTM Test Designation C 597-09: (2003). Standard Test Method for Pulse Velocity Through Concrete.

Baroghel-bouny V. (2005). New approach to concrete durability. Methodology and examples. Eng. Tech. Ed.;C2246:1-18. 
Bouakkaz, MA (2012). Characterization of Concrete using the resonant frequency method. Magister Thesis in Civil Engineering. Tlemcen, Abou Bekr Belkaid University.

Boukli H.S.M.A. (2010). Contribution to the study of the characteristic resistance of concretes in the region of Tlemcen, Doctorat thesis in Civil Engineering, University of Tlemcen.

Boukli H.S.M.A., \& Ghomari F. (2007). Study of the compression resistance of local concretes. Paper presented at: International Colloquium on Structural and Geotechnical Engineering, ICSGE; 12th Annual Colloquium. Dec 3-6.Cairo, Egypt; 1005-1014.

Boukli Hacene S.M.A., Ghomari F., \& Khelidj A. (2009). Compressive strengths of concrete formulated with Algerian local materials. Jordan J. Civ. Eng; 3: 103-117.

Dimitrios G, \& Shiotani T. (2009). Experimental study of wave propagation through grouted concrete. ACI Mater. J.; 106: 19-24.

Fathollah S, \& Payam S. (2012). High-strength lightweight concrete using leca, silica fume, and limestone. Arabian Journal for Science and Engineering, 37(7), 1885-1893.

Gesoglu M, \& Ozbay E. (2007). Effects of mineral admixtures on fresh and hardened properties of selfcompacting concretes: binary, ternary and quaternary systems. Mater. Struct.; 40: 923-937.

Giner VT, Baeza FJ, Ivorra S, et al. (2012). Effect of steel and carbon fiber additions on the dynamic properties of concrete containing silica fume. Mater. Des.34:332-339.

Han S.H, \& Kim J.K., (2004). Effect of temperature and age on the relationship between dynamic and static elastic modulus of concrete. Cem. Concr. Res; 34:1219-1227.

Hassan A. M. T. \& Jones S. W. (2012). Non-destructive testing of ultra-high performance fibre reinforced concrete (UHPFRC): A feasibility study for using ultrasonic and resonant frequency testing techniques. Construction and Building Materials, 35, 361-367.

Khan MI. (2012). Evaluation of non-destructive testing of high strength concrete incorporating supplementary cementitious composites. Resour. Conserv. Recycl. 61:125-129.

Malhotra, V. M., Carino, N.J. et al. ( 2004). Handbook on non-destructive testing of Concrete, ASTM International, West Conshohocken, PA, USA, $392 \mathrm{p}$.

Mehta PK, Monteiro PJM. (2006). Concrete - microstructure properties and materials. 3rd ed. McGrawHill.

Mirjana M, Vlastimir R, Ivan L, et al. (2014).The effect of aggregate, type and quantity of cement on modulus of elasticity of lightweight aggregate concrete. Arabian J. Sci. Eng.; 39:705-711. 